\title{
Paper-based Enzymatic Microfluidic Fuel Cell: From a two-stream flow device to a single-stream lateral flow strip
}

Maria José González-Guerrero, ${ }^{\mathrm{a}}$ F. Javier del Campo, ${ }^{* a}$ Juan Pablo Esquivel, ${ }^{\mathrm{a}, \mathrm{b}}$ FabienGiroud, ${ }^{\mathrm{c}}$ Shelley D. Minteer $^{* \mathrm{c}}$ and NeusSabaté ${ }^{* \mathrm{a}, \mathrm{d}}$

a. Instituto de Microelectrónica de Barcelona, IMB-CNM (CSIC), Campus de la Universidad Autónoma de Barcelona (Esfera UAB), 08193-Bellaterra, Barcelona, España. E-mail: javier.delcampo@csic.es; neus.sabate@imb-cnm.csic.es; Fax: +34 935801496; Tel: +34 935947700.

${ }^{b}$ Department of Bioengineering, University of Washington, 3720 15th Ave NE Seattle, WA 98195-5061, USA.

c. Departments of Chemistry and Materials Science and Engineering, University of Utah, 315 S 1400 E Rm 2020, Salt Lake City, UT 84112, USA. E-mail: minteer@chem.utah.edu; Fax: (801) 581-8433; Tel: (801) 587-8325.

${ }^{\mathrm{d}}$ Institució Catalana de Recerca i EstudisAvançats (ICREA), Barcelona, Spain.

Correspondingauthor.Maria José González-Guerrero. Tel: +34 93 5947700; Fax: +34 935801496 . Email address: mariajose.gonzalez@imb-cnm.csic.es. Postal address: Instituto de Microelectrónica de Barcelona, IMB-CNM (CSIC), Campus de la Universidad Autónoma de Barcelona (Esfera UAB), 08193Bellaterra, Barcelona, España

\begin{abstract}
This work presents a first approach towards the development of a cost-effective enzymatic paper-based glucose $/ \mathrm{O}_{2}$ microfluidic fuel cell in which fluid transport is based on capillary action. A first fuel cell configuration consists of a Y-shaped paper device with the fuel and the oxidant flowing in parallel over carbon paper electrodes modified with bioelectrocatalytic enzymes. The anode consists of a ferrocenium-based polyethyleneimine polymer linked to glucose oxidase (GOx/Fc- $\left.\mathrm{C}_{6}-\mathrm{LPEI}\right)$, while the cathode contains a mixture of laccase, anthracene-modified multiwall carbon nanotubes, and tetrabutylammonium bromide-modified Nafion (MWCNTs/laccase/TBAB-Nafion). Subsequently, the Y-shaped configuration is improved to use a single solution containing both, the anolyte and the catholyte. Thus, the electrolytes $\mathrm{pHs}$ of the fuel and the oxidant solutions are adapted to an intermediate $\mathrm{pH}$ of 5.5. Finally, the fuel cell is run with this single solution obtaining a maximum open circuit of $0.55 \pm$ $0.04 \mathrm{~V}$ and a maximum current and power density of $225 \pm 17 \mu \mathrm{A} \mathrm{cm}^{-2}$ and $24 \pm 5 \mu \mathrm{W} \mathrm{cm}$, respectively. Hence, a power source closer to a commercial application (similar to conventional lateral flow test strips) is developed and successfully operated. This system can be used to supply the energy required to power microelectronics demanding low power consumption.
\end{abstract}




\section{Keywords}

Paper-based biofuel cell

Enzymatic

Microfluidic

\section{Introduction}

Since their first appearance in the literature, microfluidic fuel cells have shown their potential for supplying power to small portable electronic devices. They are simple to operate provided that an external pressure system is coupled to the device to maintain separate flow between the anode and cathode reactants without mixing. This avoids the need for a separation membrane, typically Nafion,reduces internal ohmic losses[1], and allows for the use of different pHs at the anolyte and catholyte streams with little reagent crossover issues[2, 3]. However,the need for external pressure sources, like pumps, limits their portability and miniaturization severely [4]. Furthermore, these external pumps represent an extra energy consumption associated with the fuel cell. Although the first generation of microfluidic fuel cells was fabricated with MEMSrelated technologies, it has been demonstrated in the last years that they can also be easily made in glass or plastic [1, 5-7]using rapid prototyping techniques. Moreover, the need for external pumping has been recently overcome with the emergence of microfluidic paper devices [8-13]. These devices substitute classical microfabricated channels by a paper matrix, which provides important benefits. Paper possesses the ability to move fluids via capillary action, allowing passive liquid transport [14].As a result, no ancillary devices are needed to supply pumping functions. Furthermore, paper presents good compatibility with a high number of chemicals/biochemicals and can be combined with other low cost materials, such as plastics, to provide extra mechanical support.

For many years, paper has been widely employed as a substrate to develop point of care (POC) diagnostics devices [15]. Among them, the most broadly used POC diagnostic devices are paper-based dipsticks (urinalysis dipsticks) and lateral-flow immunoassays (pregnancy tests) [16-19]. Lately, materials used in lateral flow devices have been adapted and reconfigured into 2D or 3D paper matrices. This has led to the creation of new and exciting components, for example valves,mixers and separators [20]. In this way, the capabilities of complex microfluidic functions and the simplicity of diagnostic tests strips have been combined to originate a new generation of paper-based analytical devices ( $\mu$ PADs) [21-25]. These systems have been identified as especially suitable for point of care purposes in the field of home health-care settings and at medical points of care in developing countries [10, 12, 26,27]. This is because 
they promise to accomplish the ASSURED criteria; they are affordable, sensitive, specific, userfriendly, rapid and robust, equipment free and deliverable to those who need it [21, 25,28]. Nevertheless, the quantification of the results of a test requires the use of a hand-held reader which, in certain scenarios, is not a cost effective solution. This has brought the idea of developing low cost disposable readers; however, examples in the literature are still very scarce. To realize this vision, the search for a new generation of power sources that satisfy the requirements such as high power density, low cost and disposability with minimum environmental impact has attracted a lot of attention. In the last few years, paper has been used as a substrate to develop different kinds of power sources [29],for instance (i) fuel cells [8,9], (ii) biofuel cells, such as microbial[30, 31] and enzymatic fuel cells[32, 33],(iii) electrochemical batteries [10, 34, 35], (iv) lithium-ion batteries [36], (v) supercapacitors[37, 38] and (vi) nanogenerators[39]. Among these, biofuel cells[40], and specifically enzymatic fuel cells, appear to be one of the most suitable power sources for paper-based $\mu$ PADs in terms of environmental impact. This is because they use biological catalysts (enzymes) to convert organic fuels (commonly glucose) and oxygen into electrons, $\mathrm{CO}_{2}$, waterand/or oxidized fuel by-products[41-44].For these reasons, enzymatic fuel cells are considered extremely cost-effective and a promising future alternative source of sustainable electrical energy for small electronic devices[42, 45-48].

An intrinsic advantage of paper-based matrixes as substrates for microfluidic fuel cells is their capability of establishing laminar flow. This feature is important when considering microfluidic fuel cells as it means that, fuel and oxidant streams can flow in parallel without mixing.

In this work, we will show that the implementation of a microfluidic enzymatic fuel cell in paper allows us to eliminate the need for pumps without losing electrical performance. In order to gain simplicity in its use, the two inlets typically used in a Y-shaped fuel cell have been simplified into one inlet, so that the fuel and the electrolytes could be added together in a single step. This results in a fuel cell working with the simplicity of lateral flow test strips. This replaces the two parallel flow solutions by a single one that combines the anolyte and the catholyte components. In order to achieve this ease of use, the fuel cell has to work with a single electrolyte which required a compromise in the $\mathrm{pH}$ values between anolyte and catholyte solutions. Free from the size restrictions and power requirements of external equipment, the system presented in this paper can become an alternative for providing energy to power small single use point-of-care devices[49]. 


\section{Experimental}

\subsection{Fuel cell design and fabrication}

Two different microfluidic devices were constructed using paper, a Y-shaped and an I-shaped fuel cells. The paper selected as substrate for the systems was Whatman ${ }^{\circledR}$, grade Fusion 5, due to its high wicking rate. The system was designed using Vectorworks 2012 student edition (Techlimits, Spain). The paper sheet was attached onto a flexible plastic carrier covered with a low-strength adhesive layer to provide mechanical support during the cutting process. The paper strips were cut using a Roland GX-24 cutter plotter with a force and speed of $30 \mathrm{~g}$ and $1 \mathrm{~cm} \mathrm{~s}^{-1}$, respectively, and the cutting was performed in two passes in order to prevent any tearing of the paper [50]. The thickness of the Fusion 5 substrate (and consequently the height of the microfluidic channel) was $370 \mu \mathrm{m}$ and the fuel cells had final dimensions of $45 \times 5 \mathrm{~mm}^{2}$. After cutting, the paper structures were released from the plastic support.

Carbon paper from Fuel Cell Earth (type TG-H-060) was used as the electrodes of the fuel cells. They were cut in a rectangular size of $5 \times 15 \mathrm{~mm}^{2}$ and positioned in parallel $2 \mathrm{~cm}$ downstream (from the reactant inlets) and separated $1 \mathrm{~mm}$ from each other.In this configuration, the active electrode area exposed to the microfluidic channel is $0.10 \mathrm{~cm}^{2}$. A piece of a conducting copper tape (3M-1182) purchased from RS (Spain) was used to contact the outer part of the carbon paper electrodes. In this way the electrodes were protected from the spring loaded pins that connected the external wires. Fig. 1 (a) and (b) shows the pictures of the Y-shaped and the Ishaped paper strips together with the carbon paper electrodes.

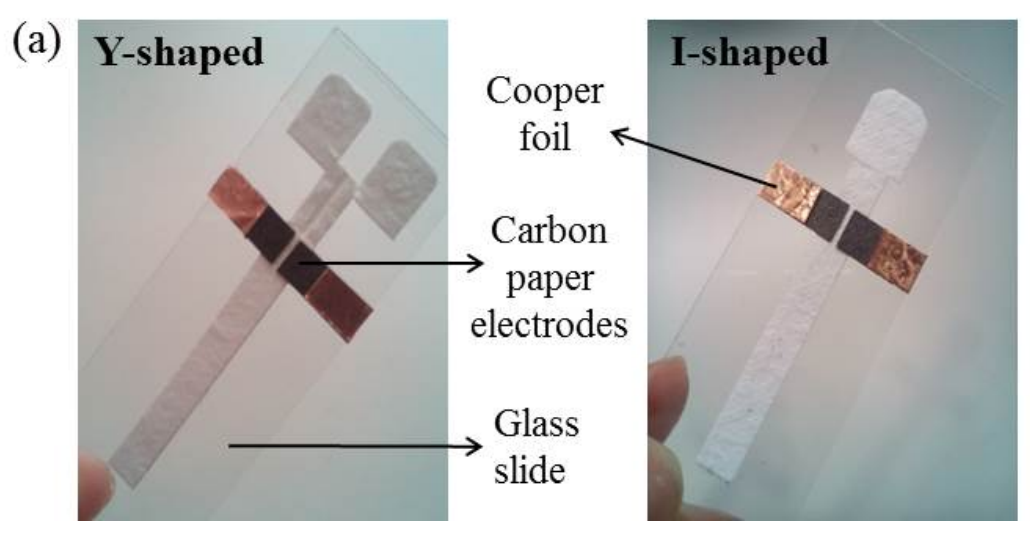

(b)

Fig. 1 (a) Y-shaped and (b) I-shaped paper fuel cells fixed on glass slides, displaying carbon paper electrodes attached to a piece of cooper foil.

\subsection{Microfluidic device assembly}

A holder made of poly(methyl methacrylate) - PMMA - was designed and made with a Roland MDX-40 milling machine (Roland DG, Spain). This component was fabricated to facilitate the 
connection of different elements of the measurement setup to the fuel cell. A pocket milled into the holder was used to hold the glass slide that supports de paper fuel cell. Two adhesive magnetic bands, placed on the sides of the PMMA block, allow fixing a PMMA bar with two fuel reservoirs at the paper inlets. Also the fuel cell wicking pad (an absorbent wipe from Kimtech Science) and the external electrical connections of the device are held by PMMA pieces. All of these plastic components host small magnets that keep them attached to the holder. For the external electrical connections, spring-loaded pins (Preci-Dip, Switzerland) were inserted in the PMMA plugs that at the same time were in contact with the copper foil over the electrodes.

\subsection{Equipment and chemicals used in the enzymatic solutions}

The salts acting as supporting electrolyte, the enzymes for the electrodes (Glucose oxidase from Aspergillus niger-EC 1.1.3.4, Type X-S, 175 units/mg of solid, 75\% protein- and laccase from Trametes Versicolor), glucose, Nafion and solvents were purchased from Sigma Aldrich and used as received. The proton conducting binder was Nafion $5 \%$ by wt. in an alcoholic suspension EW1100.Hydroxylated MWCNTs (10-30 $\mu \mathrm{m}$ length, 1.6\% - OH functionalization) were acquired from cheaptubes.com and used as received. Ethylene glycol diglycidyl ether (EGDGE) was purchased from Polyscience Inc. (Warrington, USA). 2-Anthracenecarboxylic acid was obtained from TCI chemicals and used as received.

The redox polymer $\mathrm{Fc}_{-} \mathrm{C}_{6}$-LPEI used at the anode along with the glucose oxidase was synthesized as previously reported[51].Tetrabutylammonium bromide (TBAB)-modified Nafion was prepared as previously reported[52]. Anthracene-2-carbonylchloride for anthracenemodified MWCNTs was synthesized as per previously published procedures[53, 54].

Phosphate buffer was prepared with sodium phosphate dibasic, sodium phosphate monobasic and sodium nitrate $\left(\mathrm{Na}_{2} \mathrm{HPO}_{4}, \mathrm{NaH}_{2} \mathrm{PO}_{4}\right.$ and $\left.\mathrm{NaNO}_{3}\right)$ for a final concentration of $100 \mathrm{mM}$. The $\mathrm{pH}$ of the buffer was adjusted with hydrochloric acid and sodium hydroxide $(\mathrm{HCl}$ and $\mathrm{NaOH})$ to match the optimal $\mathrm{pH}$ required by the enzymes. A $1 \mathrm{M}$ stock glucose $(\alpha-\mathrm{D}(+)$-glucose $)$ solution in distilled water was prepared 24 hours before use and stored at $4^{\circ} \mathrm{C}$ to allow it to mutarotate. Electrochemical measurements were conducted with a $\mathrm{CH}$ Instruments electrochemical workstation model 650A (Austin $\mathrm{TX}$ ). $\mathrm{Ag} / \mathrm{AgCl}$ electrode (saturated $\mathrm{KCl}$ ) and a commercial platinum electrode were used as reference and counter electrodes, respectively. All of the experiments were carried out at room temperature.

\subsection{Enzymatic bioelectrode modification}


The carbon paper electrodes were functionalized depositing polymer/enzyme solutions on them prior to their incorporation in the microfluidic fuel cell. The chemicals used to obtain the biocatalytic solutions and the process for preparing the enzyme-mixture inks are described below. The electrolyte solutions and the fuel used to run the fuel cell are also listed.

For the anodic side, the enzymatic solution was prepared with the blend of $3 \mu 1$ of enzyme glucose oxidase (10 mg ml${ }^{-1}$ in distilled water), $7 \mu \mathrm{l}$ of redox polymer $\mathrm{Fc}_{-} \mathrm{C}_{6}$-LPEI $\left(10 \mathrm{mg} \mathrm{ml}^{-1}\right.$ in distilled water) and $0.4 \mu 1$ of the crosslinker EGDGE $(10 \% \mathrm{v} / \mathrm{v})$. All of the previous components were mixed together by vortexing.

The cathodic solution was prepared by dissolving $1.5 \mathrm{mg}$ of laccase enzyme in $74 \mu 1$ of $100 \mathrm{mM}$ phosphate buffer at $\mathrm{pH} 7,7.5 \mathrm{mg}$ of anthracene modified MWCNT's and $25 \mu 1$ of TBABmodified Nafion. The above components were sonicated and vortexed intermittently until the mixture was completely suspended.

Then, $10 \mathrm{~mm}^{2}$ of carbon paper electrode was modified with $42 \mu 1$ of the corresponding enzymatic mixture by drop-casting. The electrodes were allowed to dry for 24 hours at room temperature and after this they were positioned side by side over the paper substrate with its catalytic side in contact with the paper strip. Fig. 2 shows a scheme of the reactions taking place in our biofuel cell. For clarity, the voltages associated with the reactions (vs. $\mathrm{Ag} / \mathrm{AgCl}$ reference electrode) obtained experimentally have been added.

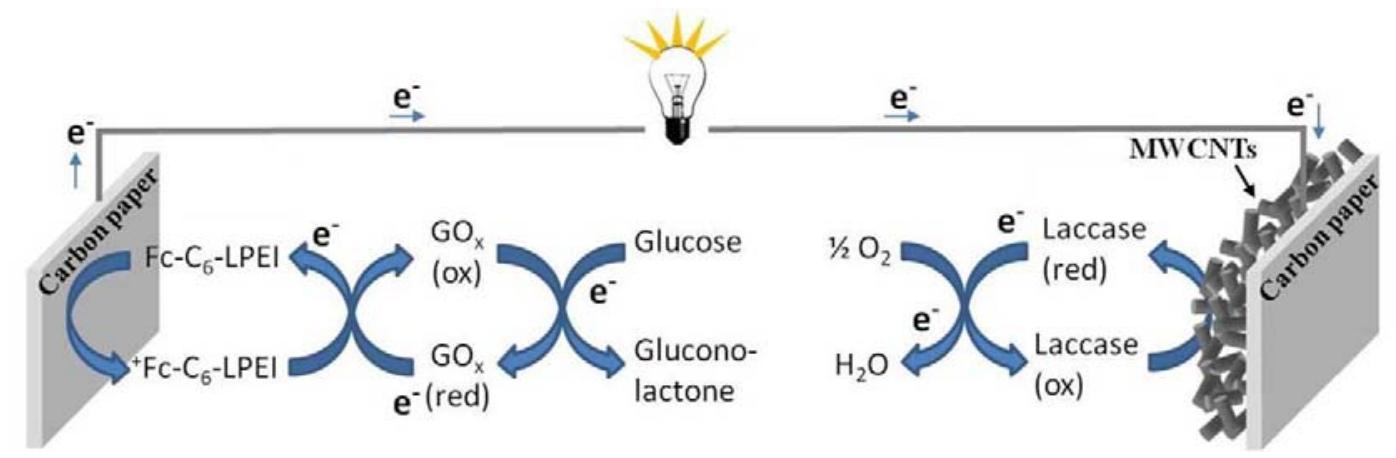

Fig. 2Depiction of the glucose/ $\mathrm{O}_{2}$ biofuel cell after enzymatic drop-coating with the reactions taking place. The figure represents the flow of electrons from the oxidation of glucose to the reduction of oxygen, showing the potentials involved in the reactions vs. $\mathrm{Ag} / \mathrm{AgCl}[7,50,54,55]$.

\section{Results and discussion}




\subsection{Operation of the $Y$-shaped flow paper fuel cell}

Microfluidic fuel cells made on paper rely on the capillary flow of reactants to cause the movement of liquids without external pressure sources. Generally, this is accomplished by attaching an absorbent pad at one end of the paper strip. Then, when a fluid is applied in the device inlet, the liquid moves through the strip until the liquid fill it and reaches the wicking pad. From this point, the flow regime is called fully-wetted [55]. In our particular case, when the advancing liquid front reaches the pad, the liquid exits a region of only $370 \mu \mathrm{m}$ thick (the strip) and enters a second porous region that is typically $>1000 \mu \mathrm{m}$ thick (the combined thickness of both the strip and the pad). From this point, a sustained flow across the strip is established[56] and the velocity of the fluidflow rate inside the paper matrix decreases very slowlydecreases from an initial value of $33.5 \mu 1 \mathrm{~min}^{-1}$ to $5 \mu 1 \mathrm{~min}^{-1}$ in a lapse of 100 minutes, Therefore, the velocity of the liquid flow rates can be estimated depending on the time interval selected to perform the experiments.

After enzymatic electrode modification, the Y-shaped paper microfluidic fuel cell is assembled in the PMMA holder shown in Fig. 3. For the fuel cell characterization, the electrolytes are selected with a $\mathrm{pH}$ that is the optimum for each enzyme. Specifically, sodium phosphate buffer at $\mathrm{pH} 7.4$ with $100 \mathrm{mM}$ glucose is applied to the anodic side, whereas phosphate buffer at $\mathrm{pH}$ 4.5 is introduced as the catholyte. Polarization experiments are performed with these solutions and the obtained curves are represented in Fig. 4. As it can be observed, the open circuit voltage is $0.6 \pm 0.05 \mathrm{~V}$ and the maximum current and power densities are $320 \pm 30 \mu \mathrm{A} \mathrm{cm}^{-2}$ and $45 \pm 9$ $\mu \mathrm{W} \mathrm{cm}$ (at $0.23 \mathrm{~V})$, respectively. Data is taken within the first 15 minutes after application of anolyte and catholyte solutions to the fuel cell. According to the values obtained from paper flow characterization (see the supplementary information for further explanation of fluid transport in paper devices) flow rates inside the paper can be considered to range from 30 to 20 $\mu 1 \mathrm{~min}^{-1}$ during the time interval of the experiments. 


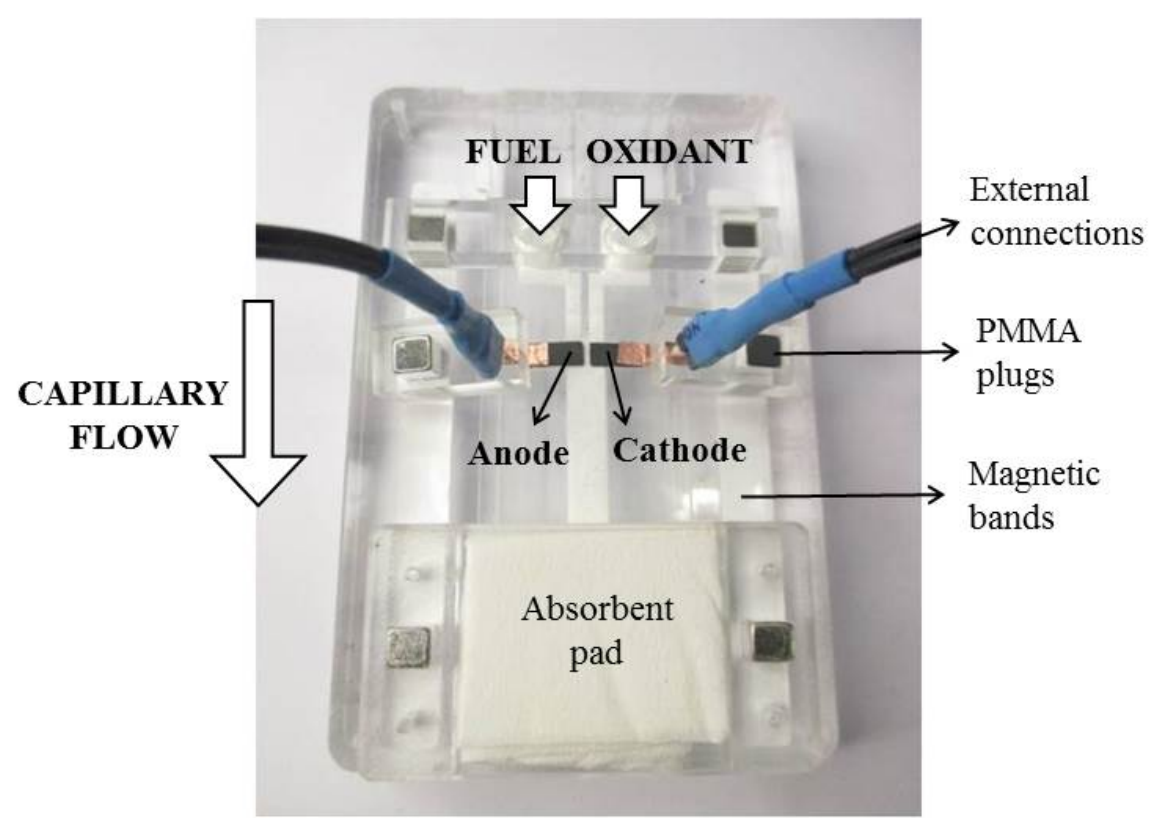

Fig. 3Y-shaped paper-based fuel cell showing the different parts forming the experimental setup for measurements.

In order to compare the power output obtained using paper to drive the fluid withthe ones obtained with a pumped microfluidic fuel cell, the maximum power densities obtained in previous published results[7] (at the same flow rates) are depicted with dashed lines in the polarization curve of Fig. 4. It can be seen that the power output achieved with the paper fuel cell is similar to the values previously obtained with the active microfluidic fuel cell (at $20 \mu 1$ $\min ^{-1}$ and $25 \mu \mathrm{min}^{-1}$ the power is $41 \mu \mathrm{W} \mathrm{cm}$ and $48 \mu \mathrm{W} \mathrm{cm}{ }^{2}$, respectively). These results demonstrate that the paper fuel cellperformance,when using the same enzymatic electrodes, is capable of producinga comparable power outputlies within the range of levels from the syringe pump range. as a fuel cell displaying active supply of liquids (such as external syringe pumps) without losing performance. Furthermore, since no energy is spent in pumping the solutions, all of the power generated can be considered as net power. Thus, our paper device represents an important simplification as compared with the typical microfluidic fuel cells that use syringe pumps. 


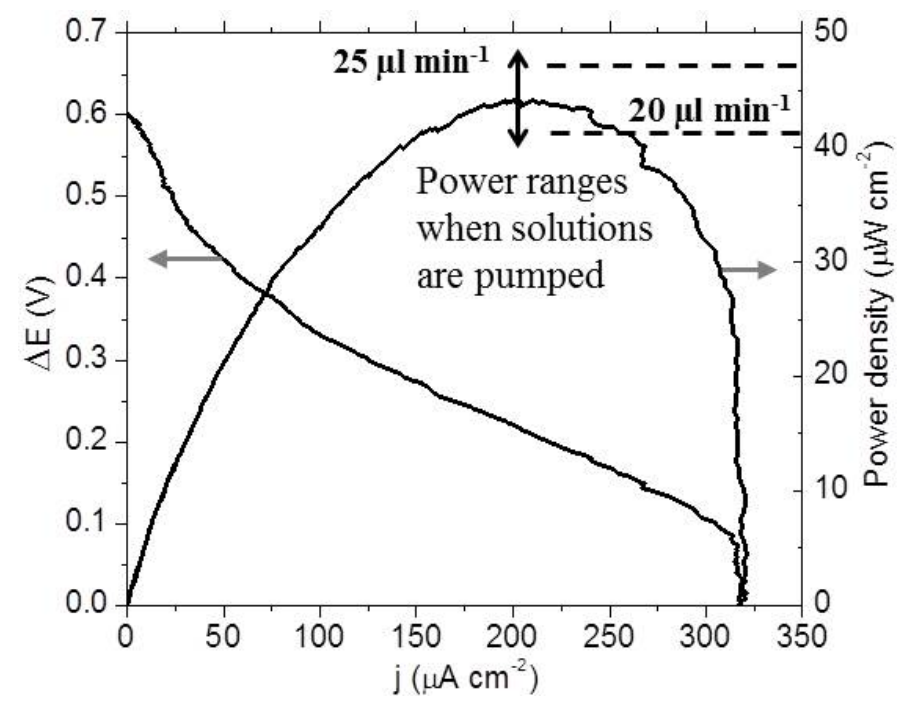

Fig. 4 Polarization and power curves for the Y-shaped microfluidic fuel cell measured at a time compressed between 10 to 15 minutes (representing a flow velocity of 20-25 $\mu 1 \mathrm{~min}^{-1}$ ). Dashed lines show the power density values for the same ranges of velocities for a fuel cell using a syringe pump instead of the capillary of paper.

\subsection{Bioelectrode characterization at different $p H s$}

In order to gain simplicity in fuel cell operation, the two inlets of the Y-shaped fuel cell can be merged into only one, so that the fuel and the electrolytes can be added together in a single step. This would result in a fuel cell working with the simplicity of lateral flow test strips. In order to achieve this simplicity, the fuel cell has to work with a single electrolyte which requires us to find a compromise in the $\mathrm{pH}$ values between anolyte and catholyte solutions. In our Y-shaped device, the fuel cell electrolytes had the optimum $\mathrm{pH}$ for each enzyme (i.e. the $\mathrm{pH}$ at which enzyme activity is maximized) corresponding to a $\mathrm{pH}$ of 4.5 for laccase and 7.4 for glucose oxidase.

With the objective of determining the $\mathrm{pH}$ at which laccase and glucose oxidase can operate losing the minimum overall fuel cell performance, glassy carbon electrodes (BASi, West Lafayette, IN)are modified with the appropriate enzyme-solution (depending if they are working as anode or cathode) and their electrochemical responses are studied at different ranges of $\mathrm{pH}$.

The catalytic behaviour of the modified glassy carbon electrodes are measured in $100 \mathrm{mM}$ phosphate buffer with $100 \mathrm{mM}$ glucose by cyclic voltammetry. The $\mathrm{pH}$ of the buffer is varied between 4.5 and 7.4 using $\mathrm{HCl}$ or $\mathrm{NaOH}$ when required. Laccases optimally operate in slightly acidic solutions, at $\mathrm{pH}$ values ranging from 3 to 5 [57]. In contrast, glucose oxidases show their better responses around neutral $\mathrm{pH}$ values [58].The voltammograms of the bioelectrodesare recorded and peak currents are extracted from each curve.Fig. 5 shows the obtained values of the current density curves achieved at the bioanode and the biocathode.These values were 
obtained after subtracting the background curves obtained with no glucose and bubbled $\mathrm{N}_{2}$, respectively. where it can be observed that an intermediate $\mathrm{pH}$ value for both enzymes can be set at around 5.5 .

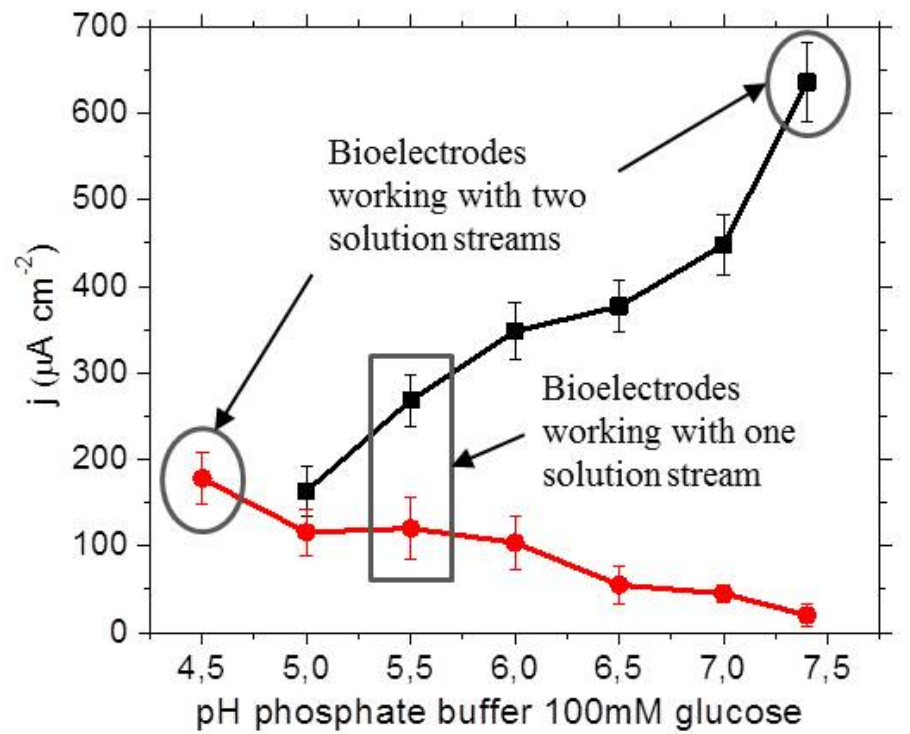

Fig. $5 \mathrm{pH}$ analysis of glassy carbon electrodes modified with the corresponding biocatalytic solution.Representation of theinfluence of $\mathrm{pH}$ on the current density at room temperature in buffer phosphate at $100 \mathrm{mM}$ and $100 \mathrm{mM}$ glucose. Red dotted-line, biocathode behavior. Blacksquared-line, response of the bioanode. The experiments are repeated three times and the error bars correspond to the standard deviation

Glassy carbon modified electrodes based on glucose oxidase (bioanode) or electrodes based on laccase (biocathode) differ considerably depending on the $\mathrm{pH}$ of the electrolyte used. These results corroborate that the fuel cell yields the best performance when $\mathrm{pH}$ of the electrolytes are 7.4 at the anode and 4.5 at the cathode. The current densities under these conditions are $635 \pm 95$ $\mu \mathrm{A} \mathrm{cm}^{-2}$ and $180 \pm 60 \mu \mathrm{A} \mathrm{cm}^{-2}$, respectively. The maximum current value that a fuel cell is able to generate is limited by the current generated from its worst performing electrode (either cathode or anode). Results in Fig. 5 indicate that the fuel cell is limited by the cathode performance, probably due to the low concentration of dissolved $\mathrm{O}_{2}$ as well as by the lower activity of the laccase as compared with the glucose oxidase. This is the reason to choose $\mathrm{pH} 5.5$ to operate the single flow fuel cell. At this pHthe laccasebiocathode showed its best performance without compromising the anode operation.

A comparison of the linear sweep voltammograms of the bioelectrodes working at $\mathrm{pH} 5.5$ and at its optimum $\mathrm{pH}$ are represented in Fig. 6. At pH 5.5, the bioanode (Fig. 6 (a)) shows a current density corresponding to $269 \pm 30 \mu \mathrm{A} \mathrm{cm}^{-2}$. At the cathode (Fig. 6 (b)) the current density is 120 $\pm 35 \mu \mathrm{A} \mathrm{cm}{ }^{-2}$, displaying a shift of about $0.05 \mathrm{~V}$ of the oxygen reduction potential towards a more negative potential when the solution at $\mathrm{pH} 5.5$ is saturated with air. 

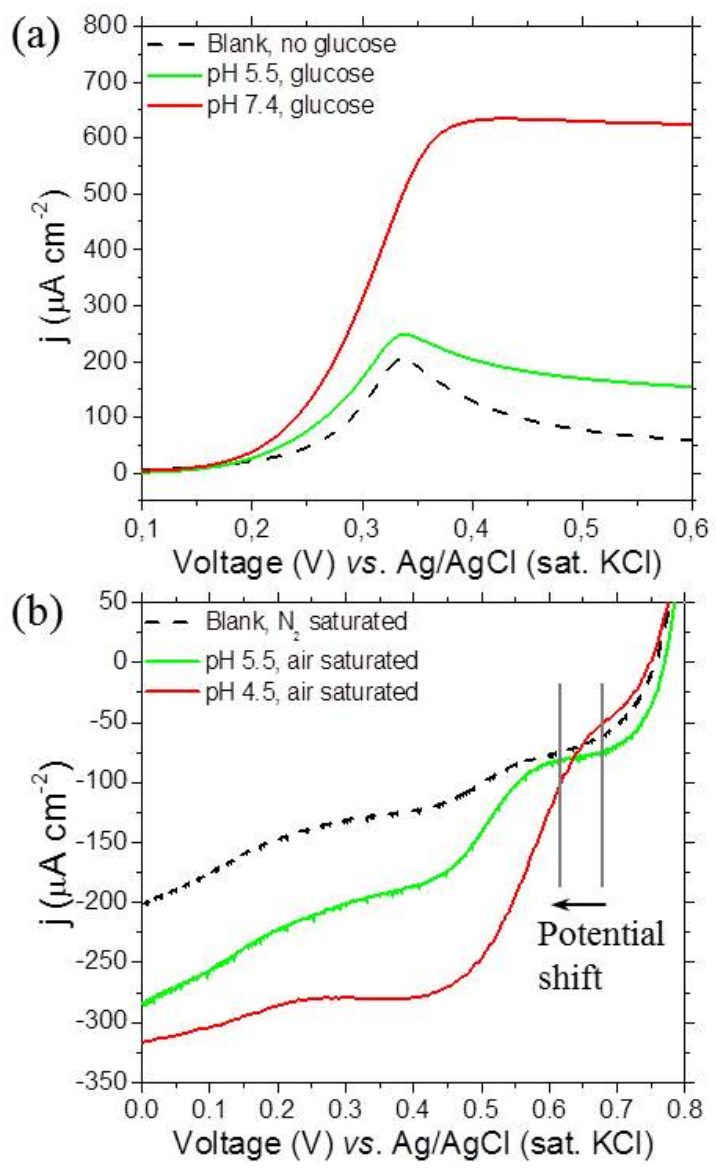

Fig. 6 Representative linear sweep voltammograms of enzymatic GC electrodes at $5 \mathrm{mV} \mathrm{s}^{-1}$. (a) $\mathrm{GOx} / \mathrm{Fc}-\mathrm{C}_{6}$-LPEI bioanodes in $100 \mathrm{mM}$ sodium phosphate at $\mathrm{pH} 7.4$ (red), at $\mathrm{pH} 5.5$ (green) and without glucose (dotted line). (b) An-MWCNTs/laccase/TBAB-Nafion biocathode in $100 \mathrm{mM}$ sodium phosphate in air saturated conditions at $\mathrm{pH} 4.5$ (red), at $\mathrm{pH} 5.5$ (green) and in $\mathrm{N}_{2}$ saturated conditions (dotted line).

\subsection{Operation of the single-stream paper fuel cell.}

The performance of the I-shaped paper fuel cell (shown in Fig. 1(b)) is measured in a solution consisting of a mixture of phosphate buffer at the intermediate $\mathrm{pH}$ of 5.5 and $100 \mathrm{mM}$ glucose. The resulting polarization and power curves are represented in Fig. 7. For comparison, the polarization and power curves that are previously obtained using the Y-shaped fuel cell are added as well.The I-shaped fuel cell yields an open circuit voltage around $0.55 \mathrm{~V} \pm 0.04$, a slightly lower value than that at the Y-shaped system. This is probably due to the potential shift in the oxygen reduction reaction that can be observed at Fig. 6 (b). The maximum current and power density of the I-shaped fuel cell are225 $\pm 17 \mu \mathrm{A} \mathrm{cm}$ and $24 \pm 5 \mu \mathrm{W} \mathrm{cm}$, respectively.The maximum current value achieved by the I-shaped fuel cell corresponds to the current valuerecorded in the linear sweep voltammetriesof anode and cathode at approximately 
$0.35 \mathrm{~V}(\mathrm{Ag} / \mathrm{AgCl})$. This corresponds to a power output drop of almost $50 \%$ compared to the $\mathrm{Y}$ shaped fuel cell in which the optimum $\mathrm{pH}$ for each enzyme is used.

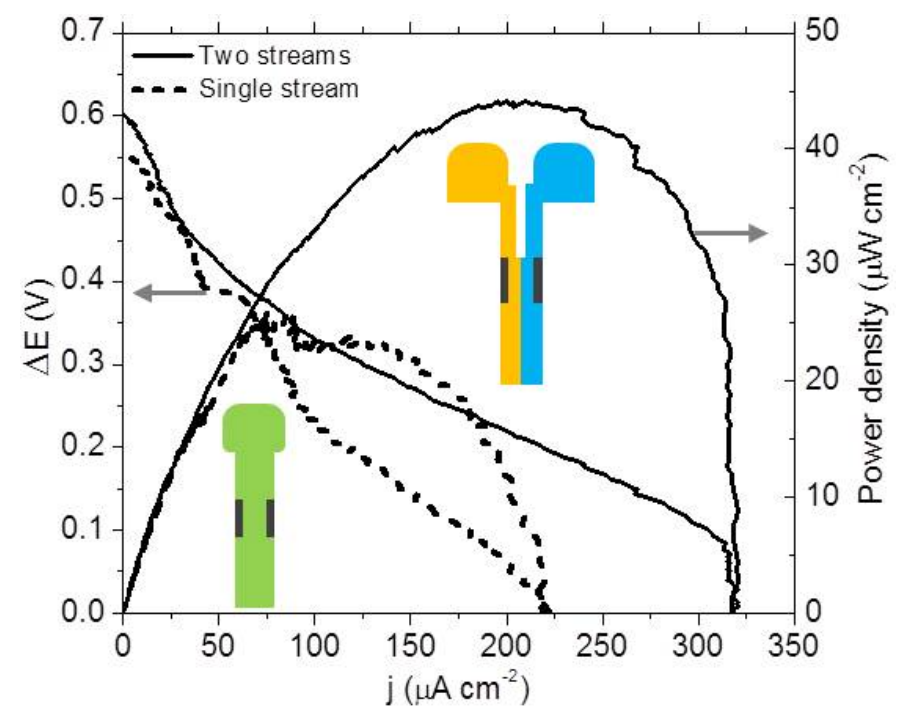

Fig. 7Polarization and power curves of two enzymatic paper-based fuel cells. Solid line shows the performance of the two stream fuel cell (Y-shaped) working with buffer phosphate at $\mathrm{pH} 4.5$ at the cathode and $\mathrm{pH} 7.4$ with $100 \mathrm{mM}$ at the anode. Dotted lines correspond to the one stream fuel cell (I-shaped) working with a single solution of sodium phosphate at $\mathrm{pH} 5.5$ with $100 \mathrm{mM}$ glucose.

The simplicity of operation of our single-stream paper fuel cell inspires the possibility of using ubiquitous fuel sources. Ultimately, biofuel cells should benefit from abundant fuel sources accessible to the general public that could use them to power small electronic devices [12]. In this context, soft drinks are cheap and broadly available in our daily lives. In fact, sugar is a very common ingredient in beverages, vegetables and fruits.

The power output of the single inlet system was tested at two additional glucose concentrations $(50$ and $400 \mathrm{mM})$ in buffer phosphate at $\mathrm{pH}$ 5.5. Results are shown in Fig. 8. It can be seen how power output decreases from $24 \mu \mathrm{W} \mathrm{cm}$ co $^{-2} 15 \mu \mathrm{W} \mathrm{cm}$ ch $^{-2}$ when glucose concentration decreases from $100 \mathrm{mM}$ to $50 \mathrm{mM}$.However, when the glucose concentration goes up to $400 \mathrm{mM}$ the system shows an intermediate power output of $19 \mu \mathrm{W} \mathrm{cm}{ }^{-2}$. This result is consistent with those reported in the literature for similarenzymatic fuel cells. Generally, this kind of fuel cells shown a power output saturation at around $100 \mathrm{mM}$ glucose and an increase in glucose concentration does not yield a better fuel cell performance. On the contrary, in this case at high glucose concentrations a diminution of the current and power density of the system was observed. This could be due to an increase of the electrolyte viscosity, which diminishes the velocity of the flow. It has been reported that increasing glucose concentration in an aqueous 
fluid from $100 \mathrm{mM}$ to $400 \mathrm{mM}$ increases viscosity from 1.0 Pa·s to approximately $1.4 \mathrm{~Pa} \cdot \mathrm{s}[59]$. Indeed, the volumetric flow rate $(\mathrm{Q})$ is related to the viscosity $(\mu)$ : $Q \sim 1 / \mu$. Consequently, the velocity of the liquid inside the microchannel decreases and this gives rise to a decrease of the power output of the system.

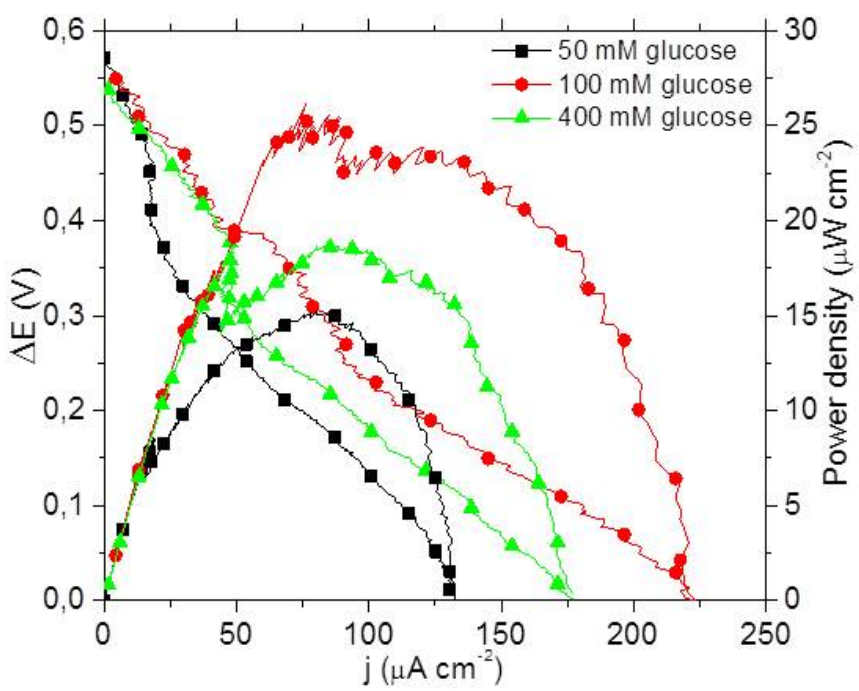

Fig. 8Polarization and power curves of the I-shaped paper-based enzymatic fuel cell working with a single solution stream using phosphate buffer at pH 5.5 with $50 \mathrm{mM}, 100 \mathrm{mM}$ and 400 $\mathrm{mM}$ glucose.

In summary, it is demonstrated that the single stream enzymatic paper-based fuel cell is able to work properly despite showing lower performance as compared with the Y-shaped fuel cell. However, the fuel cell format presented is much closer in design to lateral flow test strips which gives the system important advantages toward commercial applications[8].

\section{Conclusions}

In this paper, we have demonstrated that it is possible to run a paper-based microfluidic fuel cell producing about the same power output as the microfuel cell presented in previously published work [7], where an external syringe pump was used for the supply of reactants. Our fuel cell represents a great simplification as compared to the previous one, as it allows us to obtain electrical power without any ancillary devices. Second, the system was further simplified. For this purpose, the paper-based fuel cell was operated using a single solution instead of the two streams employed in conventional Y-shaped fuel cells. That implied the need of finding a compromise between anolyte and catholyte $\mathrm{pHs}$, a value that was set at 5.5, after carefully studying the enzymatic performance of the bioelectrodes at different solution pHs. 
The single stream fuel cell was characterized at $100 \mathrm{mM}$ glucose in an electrolyte at $\mathrm{pH}$ 5.5. The values obtained were: $0.55 \mathrm{~V}$ at the open circuit voltage, a maximum current density of $225 \pm$ $17 \mu \mathrm{A} \mathrm{cm}^{-2}$ and a maximum power density of $24 \pm 5 \mu \mathrm{W} \mathrm{cm}$ (at $0.35 \mathrm{~V}$ ). Although the efficiency of the system decreases compared with the Y-shaped microfluidic fuel cell, the single-stream configuration is much easier to be implemented in a real application.

The presented fuel cell performance and its simplicity of operation inspires the possibility of using ubiquitous fuel sources to generate power [60]. In this context, soft drinks (whose pH range from 3 to 6 ) can be used to generate electrical energy and feed small electronic devices because they are cheap, broadly available and have high contents of sugar.

Finally, the I-shaped paper device was tested at different glucose concentrations. It was observed that very high glucose concentrations (such as $400 \mathrm{mM}$ ) led to a decrease of the power output and it was attributed to an increase in the liquid viscosity that causes a significant reduction in the flow rate.

In conclusion, the enzymatic paper-based microfluidic fuel cell presented here exhibits multiple benefits as compared with traditional microfluidic fuel cells. On the other hand, the limited lifetimes of enzymes restrict their application to portable power deviceswhere long-term operation is not required $[42,61]$. In this sense, associating these biological fuel cells with the advantage of paper networks can be significant for developing inexpensive, mass-producible, and portable diagnostic devices.

\section{Acknowledgements}

F. Javier del Campo acknowledges funding from the Spanish Ministry of Economy through the DADDi2 project (TEC2013-48506-C3). Juan Pablo Esquivel would like to thank the support from Marie Curie International Outgoing Fellowship (APPOCS) within the 7th European Community Framework Programme. Shelley D. Minteer and Fabien Giroud would like to thank the National Science Foundation for funding. NeusSabaté acknowledges funding from the European H2020 Framework Programme (Grant Agreement 648518 - SUPERCELL - ERC $2014 \mathrm{CoG})$.

\section{References}

[1] E. Kjeang, N. Djilali, D. Sinton, Journal of Power Sources, 186 (2009) 353-369. 
[2] R.S. Jayashree, L. Gancs, E.R. Choban, A. Primak, D. Natarajan, L.J. Markoski, P.J. Kenis, Journal of the American Chemical Society, 127 (2005) 16758-16759.

[3] E.R. Choban, L.J. Markoski, A. Wieckowski, P.J.A. Kenis, Journal of Power Sources, 128 (2004) 54-60.

[4] A. Zebda, C. Innocent, L. Renaud, M. Cretin, F. Pichot, R. Ferrigno, S. Tingry, Enzyme-Based Microfluidic Biofuel Cell to Generate Micropower, 2011.

[5] M.T. Meredith, S.D. Minteer, Annual Review of Analytical Chemistry, Vol 5, 5 (2012) 157179.

[6] J. Atencia, D.J. Beebe, Nature, 437 (2005) 648-655.

[7] M.J. Gonzalez-Guerrero, J. Pablo Esquivel, D. Sanchez-Molas, P. Godignon, F. Xavier Munoz, F. Javier del Campo, F. Giroud, S.D. Minteer, N. Sabate, Lab on a Chip, 13 (2013) 2972-2979.

[8] J.P. Esquivel, F.J. Del Campo, J.L. Gomez de la Fuente, S. Rojas, N. Sabate, Energy \& Environmental Science, 7 (2014) 1744-1749.

[9] R.K. Arun, S. Halder, N. Chanda, S. Chakraborty, Lab on a Chip, 14 (2014) 1661-1664.

[10] N.K. Thom, G.G. Lewis, M.J. DiTucci, S.T. Phillips, RSC Advances, 3 (2013) 6888-6895.

[11] E.J. Maxwell, A.D. Mazzeo, G.M. Whitesides, MRS bulletin, 38 (2013) 309-314.

[12] Z. Nie, C.A. Nijhuis, J. Gong, X. Chen, A. Kumachev, A.W. Martinez, M. Narovlyansky, G.M. Whitesides, Lab on a Chip, 10 (2010) 477-483.

[13] L. Hu, H. Wu, F. La Mantia, Y. Yang, Y. Cui, Acs Nano, 4 (2010) 5843-5848.

[14] D.D. Liana, B. Raguse, J.J. Gooding, E. Chow, Sensors, 12 (2012) 11505-11526.

[15] J. Hu, S. Wang, L. Wang, F. Li, B. Pingguan-Murphy, T.J. Lu, F. Xu, Biosensors and Bioelectronics, 54 (2014) 585-597.

[16] A.W. Martinez, Bioanalysis, 3 (2011) 2589-2592.

[17] P. von Lode, Clinical Biochemistry, 38 (2005) 591-606.

[18] C.D. Chin, S.Y. Chin, T. Laksanasopin, S.K. Sia, Low-cost microdevices for point-of-Care testing, in: Point-of-Care Diagnostics on a Chip, Springer, 2013, pp. 3-21.

[19] P. Shah, X. Zhu, C.Z. Li, Expert Review of Molecular Diagnostics, 13 (2013) 83-91.

[20] P. Lisowski, P.K. Zarzycki, Chromatographia, 76 (2013) 1201-1214.

[21] E. Jane Maxwell, A.D. Mazzeo, G.M. Whitesides, MRS Bulletin, 38 (2013) 309-314.

[22] A.W. Martinez, S.T. Phillips, G.M. Whitesides, E. Carrilho, Analytical Chemistry, 82 (2009) 3-10.

[23] H. Liu, R.M. Crooks, Analytical chemistry, 84 (2012) 2528-2532.

[24] C. Chin, S. Chin, T. Laksanasopin, S. Sia, Low-Cost Microdevices for Point-of-Care Testing, in: D. Issadore, R.M. Westervelt (Eds.) Point-of-Care Diagnostics on a Chip, Springer Berlin Heidelberg, 2013, pp. 3-21.

[25] C. Zhao, M.M. Thuo, X. Liu, Science and Technology of Advanced Materials, 14 (2013) 54402-54408.

[26] W. Dungchai, O. Chailapakul, C.S. Henry, Analytical chemistry, 81 (2009) 5821-5826.

[27] B.A. Zaccheo, R.M. Crooks, Analytical chemistry, 83 (2011) 1185-1188.

[28] R.W. Peeling, K.K. Holmes, D. Mabey, A. Ronald, Sexually Transmitted Infections, 82 (2006) V1-V6.

[29] F. Sharifi, S. Ghobadian, F.R. Cavalcanti, N. Hashemi, Renewable and Sustainable Energy Reviews, 52 (2015) 1453-1472.

[30] R. Veerubhotla, A. Bandopadhyay, D. Das, S. Chakraborty, Lab on a Chip, 15 (2015) 25802583.

[31] J. Winfield, L.D. Chambers, J. Rossiter, J. Greenman, I. Ieropoulos, Journal of Materials Chemistry A, 3 (2015) 7058-7065.

[32] L. Zhang, M. Zhou, D. Wen, L. Bai, B. Lou, S. Dong, Biosensors and Bioelectronics, 35 (2012) 155-159.

[33] G.P.M.K. Ciniciato, C. Lau, A. Cochrane, S.S. Sibbett, E.R. Gonzalez, P. Atanassov, Electrochimica Acta, 82 (2012) 208-213.

[34] K.B. Lee, Journal of Micromechanics and Microengineering, 16 (2006) 2312. 
[35] K.B. Lee, Journal of Micromechanics and Microengineering, 15 (2005) S210.

[36] S. Leijonmarck, A. Cornell, G. Lindbergh, L. Wagberg, Journal of Materials Chemistry A, 1 (2013) 4671-4677.

[37] L. Ge, P. Wang, S. Ge, N. Li, J. Yu, M. Yan, J. Huang, Analytical Chemistry, 85 (2013) 39613970.

[38] L. Nyholm, G. Nyström, A. Mihranyan, M. Strømme, Advanced Materials, 23 (2011) 37513769.

[39] Q. Zhong, J. Zhong, B. Hu, Q. Hu, J. Zhou, Z.L. Wang, Energy \& Environmental Science, 6 (2013) 1779-1784.

[40] T.H. Nguyen, A. Fraiwan, S. Choi, Biosensors \& Bioelectronics, 54 (2014) 640-649.

[41] T. Beneyton, I.P.M. Wijaya, C. Ben Salem, A.D. Griffiths, V. Taly, Chemical Communications, 49 (2013) 1094-1096.

[42] J.w. Lee, E. Kjeang, Biomicrofluidics, 4 (2010) 041301.

[43] M. Zhou, C. Chen, Y. Du, B. Li, D. Wen, S. Dong, E. Wang, Lab on a Chip, 10 (2010) 29322936.

[44] J.A. Cracknell, K.A. Vincent, F.A. Armstrong, Chemical Reviews, 108 (2008) 2439-2461. [45] R.A. Bullen, T.C. Arnot, J.B. Lakeman, F.C. Walsh, Biosensors and Bioelectronics, 21 (2006) 2015-2045.

[46] M.H. Osman, A.A. Shah, F.C. Walsh, Biosensors and Bioelectronics, 26 (2011) 3087-3102. [47] E. Katz, A. Shipway, I. Willner, Biochemical Fuel Cells, 1 (2003) 1-27.

[48] A.K. Shukla, P. Suresh, S. Berchmans, A. Rajendran, Current Science, 87 (2004) 455-468.

[49] S. Calabrese Barton, J. Gallaway, P. Atanassov, Chemical Reviews, 104 (2004) 4867-4886.

[50] D.M. Cate, J.A. Adkins, J. Mettakoonpitak, C.S. Henry, Analytical chemistry, 87 (2014) 1941.

[51] S.A. Merchant, M.T. Meredith, T.O. Tran, D.B. Brunski, M.B. Johnson, D.T. Glatzhofer, D.W. Schmidtke, The Journal of Physical Chemistry C, 114 (2010) 11627-11634.

[52] T. Klotzbach, M. Watt, Y. Ansari, S.D. Minteer, Journal of Membrane Science, 282 (2006) 276-283.

[53] M.T. Meredith, M. Minson, D. Hickey, K. Artyushkova, D.T. Glatzhofer, S.D. Minteer, ACS Catalysis, 1 (2011) 1683-1690.

[54] A. Dawn, T. Shiraki, S. Haraguchi, H. Sato, K. Sada, S. Shinkai, Chemistry-a European Journal, 16 (2010) 3676-3689.

[55] Aut^hor, in: Microfluidics 2.0, 2010.

[56] S. Mendez, E.M. Fenton, G.R. Gallegos, D.N. Petsev, S.S. Sibbett, H.A. Stone, Y. Zhang, G.P. López, Langmuir, 26 (2010) 1380-1385.

[57] P. Baldrian, Fems Microbiology Reviews, 30 (2006) 215-242.

[58] M.T. Meredith, D.-Y. Kao, D. Hickey, D.W. Schmidtke, D.T. Glatzhofer, Journal of the Electrochemical Society, 158 (2011) B166-B174.

[59] E. Kim, (2010).

[60] F. Nolan-Neylan, Chemistry World, 8 (2011) 23-23.

[61] J. Kim, H.F. Jia, P. Wang, Biotechnology Advances, 24 (2006) 296-308. 
(a) Y-shaped

Cooper

I-shaped foil

Carbon paper

electrodes

fig 1

Glass

slide 
fig 2

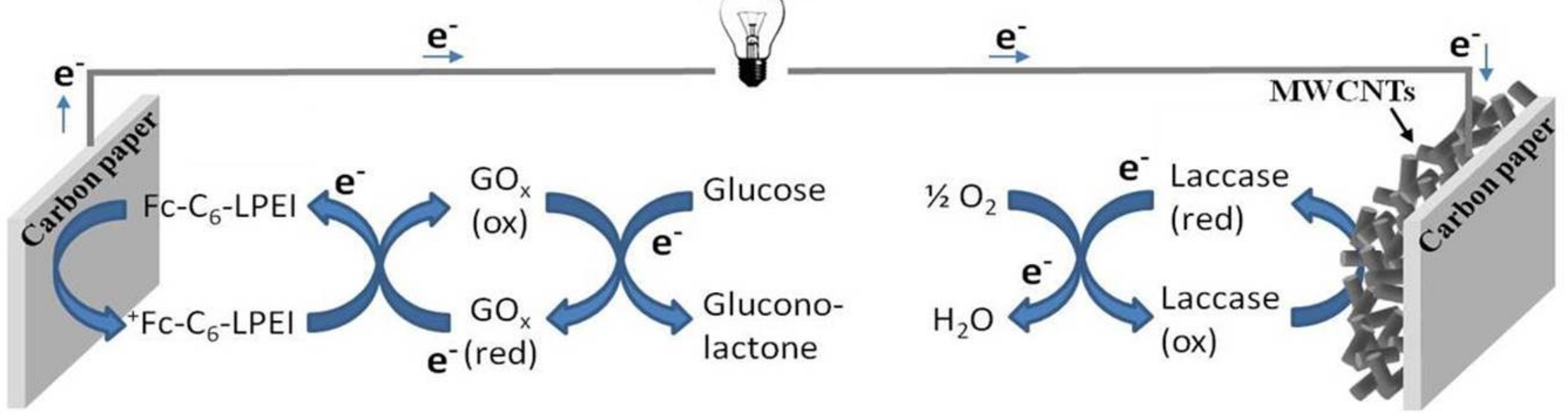




\section{FUEL OXIDANT}

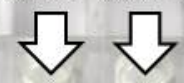

External connections

CAPILLARY FLOW

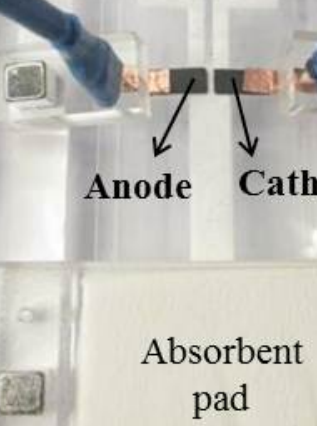

fig 3

PMMA plugs

Magnetic bands 


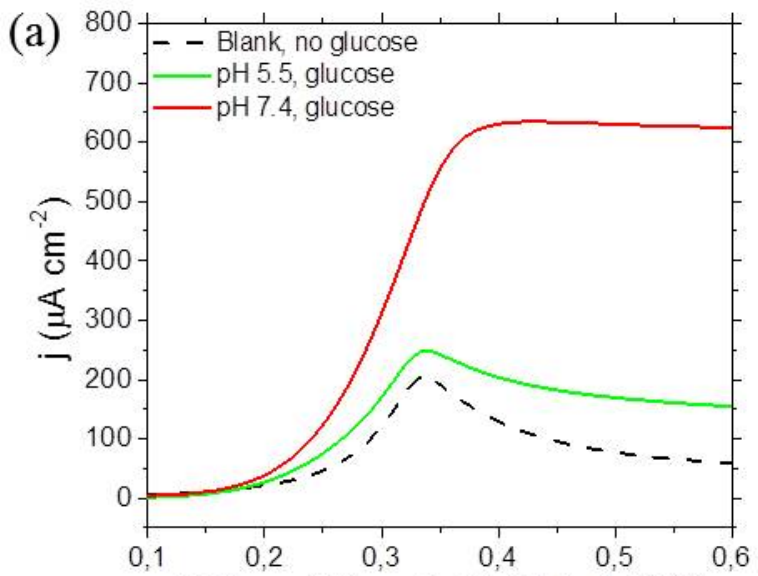

Voltage (V) vs. $\mathrm{Ag} / \mathrm{AgCl}$ (sat. $\mathrm{KCl}$ )

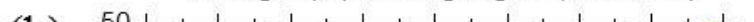

(b) $50+\frac{1}{1} \frac{1}{1} \frac{1}{1}, \frac{1}{1}$

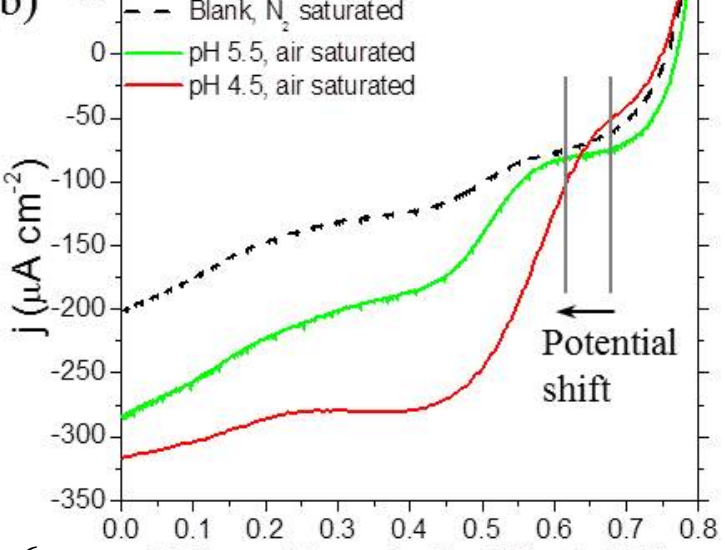

fig $6 \quad$ Voltage (V) vs. $\mathrm{Ag} / \mathrm{AgCl}$ (sat. $\mathrm{KCl}$ ) 


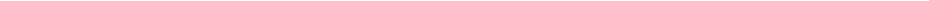




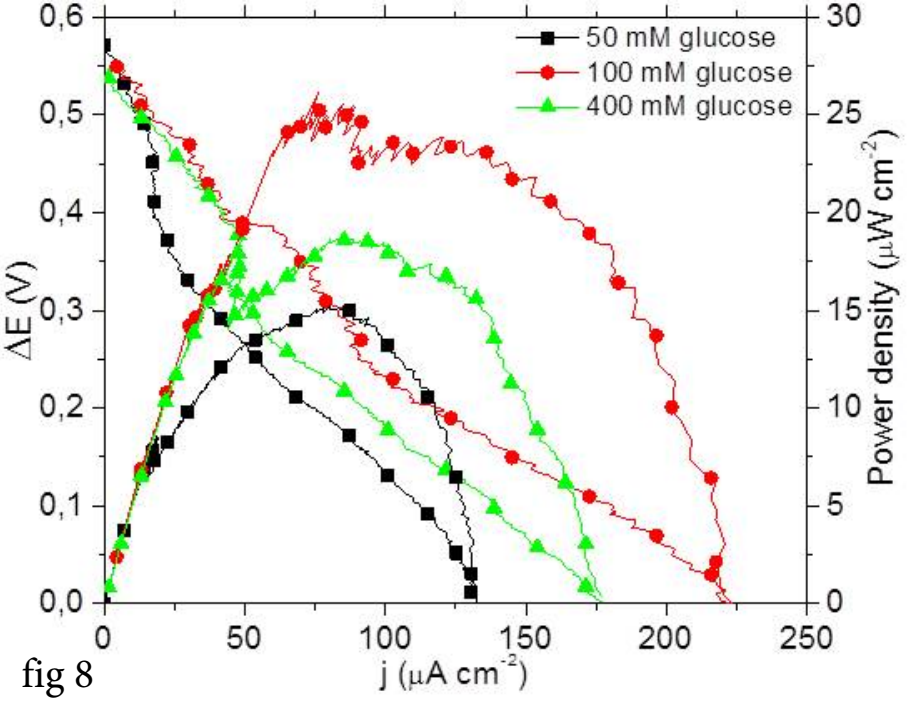

